С. Д. БРИНКЕВИЧ, О. И. ШАДЫРО

\title{
ВЛИЯНИЕ АСКОРБИНОВОЙ КИСЛОТЫ И ЕЕ ПРОИЗВОДНЫХ НА РАДИАЦИОННО-ИНДУЦИРОВАННЫЕ ПРЕВРАЩЕНИЯ ОКСИГЕНИРОВАННОГО ЭТАНОЛА И ЕГО ВОДНЫХ РАСТВОРОВ
}

Аскорбиновая кислота (AК) является одним из важнейших регуляторов свободнорадикального гомеостаза в организме человека. Она выступает кофактором гидроксилаз и монооксигеназ, вовлеченных в синтез коллагена, карнитина, желчных кислот и нейротрансмитеров, а также детоксикацию ксенобиотиков [1]. За счет способности акцептировать активные формы кислорода в водной фазе и восстанавливать радикалы жирорастворимых антиоксидантов, в первую очередь токоферола, АК предотвращает свободнорадикальное повреждение биосистем [2]. Поэтому она широко используется в медицине для профилактики и лечения вирусных, онкологических, сердечно-сосудистых, нейродегенеративных и других заболеваний, сопровождающихся гиперпродукцией активных форм кислорода и активацией перекисного окисления липидов (ПОЛ) $[1,3]$. В то же время в ряде исследований, проведенных на клеточных культурах и животных, было показано, что АК 
способна выступать как прооксидант, увеличивая уровни маркеров ПОЛ и свободнорадикального повреждения ДНК $[4,5]$. Считается, что этот эффект обусловлен восстановлением ионов железа и других металлов переменной валентности, вступающих с $\mathrm{H}_{2} \mathrm{O}_{2}$ и органическими гидропероксидами в реакции типа Фентона [5].

Метод стационарного радиолиза позволяет генерировать различные типы свободных радикалов, образующихся в биосистемах, и установить механизм взаимодействия тестируемых соединений с радикальными частицами. Настоящая работа посвящена изучению влияния аскорбиновой кислоты, ее 2-О-гликозилированного и полностью алкилированного аналогов на выходы основных молекулярных продуктов радиолиза оксигенированного этанола и его водных растворов при рН 7.

\section{МЕТОДИКА ЭКСПЕРИМЕНТА}

В работе использовалась аскорбиновая кислота фирмы Sigma-Aldrich; 5,6-О-изопропилидил-2,3-О-диметиласкорбиновая кислота (ИДМАК) синтезировалась по методике [6]; 2-О-глюкопиранозиласкорбиновая кислота (ГАК) была предоставлена CCI Corporation (Japan). Структурные формулы использованных соединений представлены ниже:<smiles>O=C1OC(C(O)CO)C(O)=C1O</smiles>

аскорбиновая кислота

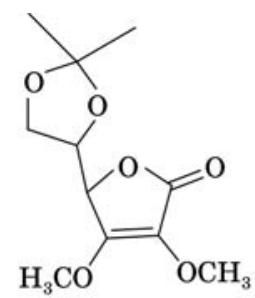

5,6-О-изопропилидил2,3-О-диметиласкорбиновая кислота<smiles>O=C1OC(C(O)CO)C(O)=C1OC1OC(O)C(O)C(O)C1O</smiles>

2-О-гликозид аскорбиновой кислоты (ГАК)

Этанол-ректификат (96 об. \% ) перед использованием очищался сорбцией на цеолите марки Wolfen Zeosorb LA с последующей перегонкой. Для приготовления водных растворов с $\mathrm{pH} 7 \pm 0,05$ навески тестируемых соединений растворяли в приготовленном на бидистиллированной воде фосфатном буфере. Водные растворы насыщали кислородом в ампулах в течение 60 мин, после чего запаивали. Спиртовые растворы готовили на предварительно оксигенированном этаноле. Облучение проводили на установке MPX- $\gamma$-25M с источником ${ }^{60} \mathrm{Co}$. Мощность поглощенной дозы составляла 0,50 $\pm 0,016 \mathrm{\Gamma p} / \mathrm{c}$, интервал поглощенных доз - 0,18-0,90 кГр.

Ацетальдегид определяли методом газожидкостной хроматографии в соответствии с [7], пероксид водорода - реагентно-спектрофотометрическим методом, основанным на образовании желтого комплекса пероксида водорода с сульфатом титанила в сернокислом растворе [8]. Концентрацию тестируемых соединений в растворах определяли спектрофотометрически на Specord M40. Радиационно-химические выходы образования продуктов радиолиза и расходования добавок рассчитывали на линейных участках за- 
висимости концентраций веществ от поглощенной дозы с использованием метода наименьших квадратов. Приведенные в работе величины радиационно-химических выходов являются результатом усреднения трех независимых экспериментов.

\section{РЕЗУЛЬТАТЫ И ИХ ОБСУЖДЕНИЕ}

При радиолизе этанола, насыщенного кислородом, основными молекулярными продуктами являются ацетальдегид и пероксид водорода, образующиеся по следующей схеме [9]:

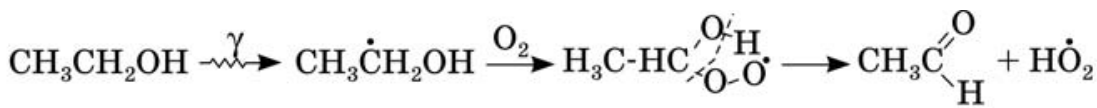

$$
\begin{aligned}
& \mathrm{HO}_{2}+\mathrm{CH}_{3} \mathrm{CH}_{2} \mathrm{OH} \longrightarrow \mathrm{H}_{2} \mathrm{O}_{2}+\mathrm{CH}_{3} \dot{\mathrm{C}} \mathrm{HOH} \\
& 2 \mathrm{HO}_{2} \longrightarrow \mathrm{H}_{2} \mathrm{O}_{2}+\mathrm{O}_{2}
\end{aligned}
$$

При радиолизе АК в насыщенном кислородом этаноле наблюдаются высокие выходы разложения добавки, что свидетельствует о ее высокой реакционной способности по отношению к образующимся в данной системе радикальным частицам. В работе [7] было показано, что АК способна эффективно подавлять радиационно-индуцированные превращения деаэрированного этанола за счет окисления $\alpha$-гидроксиэтильных радикалов ( $\alpha-\Gamma Э Р)$. Реализация данного механизма при радиолизе оксигенированного этанола в присутствии АК приводила бы к увеличению выходов ацетальдегида. Представленные в таблице данные свидетельствуют об уменьшении выходов как ацетальдегида, так и пероксида водорода при облучении оксигенированного этанола в присутствии добавки. Поэтому наблюдаемые эффекты могут быть обусловлены восстановлением $\alpha-\Gamma Э Р$ по реакции:<smiles>CCO[CH+]CCCCOC(O)C1OC(=O)C(O)=C1O</smiles>

Радиационно-химические выходы разложения ГАК, а также ее влияние на выходы продуктов радиолиза оксигенированного этанола указывают на низкую реакционную способность данного соединения по отношению к $\alpha$-ГЭР; незначительное увеличение выходов $\mathrm{H}_{2} \mathrm{O}_{2}$ может быть обусловлено восстановлением гидропероксильных радикалов добавкой:

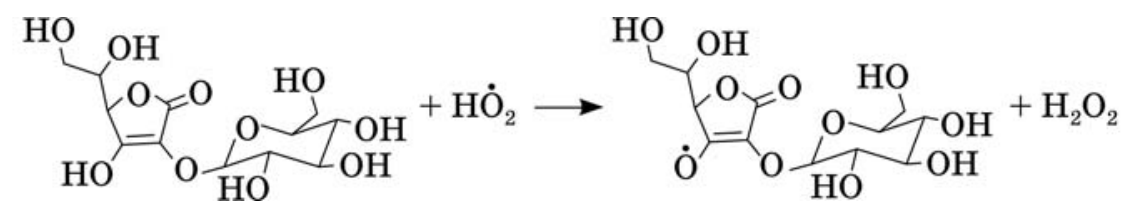


При радиолизе оксигенированого этанола в присутствии ИДМАК происходит увеличение радиационно-химического выхода ацетальдегида при снижении выхода пероксида водорода, что свидетельствует об окислении $\alpha-\Gamma Э Р$ добавкой:

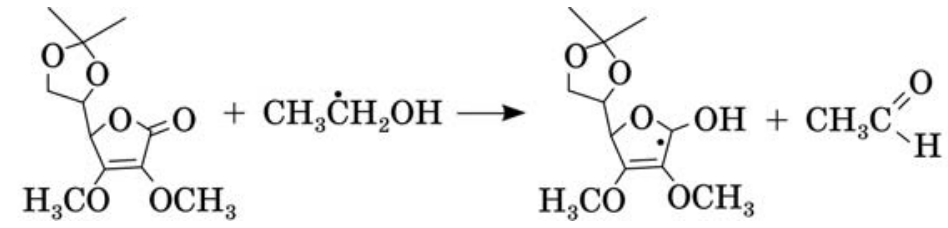

Влияние АК, ГАК и ИДМАК на радиационно-индуцированные превращения оксигенированного этанола и его водных растворов при рН 7

\begin{tabular}{|c|c|c|c|}
\hline \multirow{2}{*}{$\begin{array}{c}\text { Добавки, } \\
c=10^{-3} \text { моль } / \text { л }\end{array}$} & \multicolumn{3}{|c|}{ Радиационно-химические выходы $(G)$, молекула/100 эВ } \\
\hline & Ацетальдегид & Пероксид водорода & Разложение добавки \\
\hline \multicolumn{4}{|c|}{96 \% этанол } \\
\hline Без добавок & $7,06 \pm 0,28$ & $7,54 \pm 0,27$ & \\
\hline $\mathrm{AK}$ & $4,69 \pm 0,26$ & $5,69 \pm 0,14$ & $-2,91 \pm 0,14$ \\
\hline ГАК & $7,64 \pm 0,29$ & $7,81 \pm 0,25$ & $-0,78 \pm 0,05$ \\
\hline ИДМАК & $9,43 \pm 0,30$ & $6,42 \pm 0,28$ & $-0,15 \pm 0,02$ \\
\hline \multicolumn{4}{|c|}{ Концентрация этанола 1 моль/дм ${ }^{3}$} \\
\hline Без добавок & $4,31 \pm 0,23$ & $2,73 \pm 0,18$ & \\
\hline $\mathrm{AK}$ & $4,09 \pm 0,30$ & $1,98 \pm 0,20$ & $-3,48 \pm 0,26$ \\
\hline ГАК & $4,12 \pm 0,23$ & $2,72 \pm 0,20$ & $-0,17 \pm 0,01$ \\
\hline ИДМАК & $4,45 \pm 0,11$ & $2,36 \pm 0,18$ & $-0,32 \pm 0,04$ \\
\hline \multicolumn{4}{|c|}{ Концентрация этанола $10^{-1}$ моль $/$ дм $^{3}$} \\
\hline Без добавок & $3,79 \pm 0,014$ & $2,18 \pm 0,05$ & \\
\hline $\mathrm{AK}$ & $3,19 \pm 0,26$ & $1,45 \pm 0,16$ & $-3,85 \pm 0,38$ \\
\hline ГАК & $3,59 \pm 0,12$ & $2,15 \pm 0,05$ & $-0,31 \pm 0,04$ \\
\hline ИДМАК & $4,31 \pm 0,22$ & $1,78 \pm 0,09$ & $-0,54 \pm 0,08$ \\
\hline \multicolumn{4}{|c|}{ Концентрация этанола $10^{-2}$ моль/дм ${ }^{3}$} \\
\hline Без добавок & $2,43 \pm 0,11$ & $2,06 \pm 0,11$ & \\
\hline $\mathrm{AK}$ & $1,96 \pm 0,15$ & $1,13 \pm 0,10$ & $-4,77 \pm 0,30$ \\
\hline ГАК & $2,36 \pm 0,19$ & $1,90 \pm 0,08$ & $-1,24 \pm 0,12$ \\
\hline ИДМАК & $2,53 \pm 0,12$ & $1,44 \pm 0,11$ & $-1,21 \pm 0,15$ \\
\hline \multicolumn{4}{|c|}{ Концентрация этанола $10^{-3}$ моль $/$ дм $^{3}$} \\
\hline Без добавок & $1,56 \pm 0,14$ & $1,39 \pm 0,04$ & \\
\hline $\mathrm{AK}$ & $0,59 \pm 0,15$ & $1,10 \pm 0,20$ & $-5,62 \pm 0,25$ \\
\hline ГАК & $0,69 \pm 0,10$ & $1,42 \pm 0,05$ & $-2,48 \pm 0,21$ \\
\hline ИДМАК & $1,07 \pm 0,11$ & $1,12 \pm 0,20$ & $-2,69 \pm 0,23$ \\
\hline
\end{tabular}


Реализация такого типа реакции должна приводить к значительным выходам разложения добавки. Однако при радиолизе в оксигенированном этаноле разложение ИДМАК не наблюдается, что может указывать на возможность регенерации добавки, например, за счет реакции:

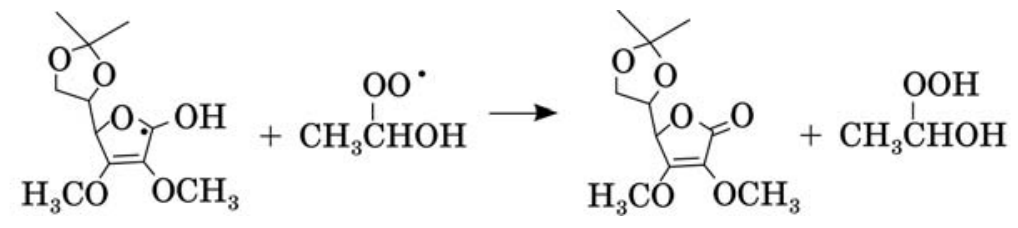

При облучении водных растворов этанола, насыщенных кислородом, свободнорадикальные процессы инициируются радикальными продуктами радиолиза воды [9]:

$$
\begin{aligned}
& \mathrm{H}_{2} \mathrm{O} \rightarrow \stackrel{\sim}{\rightarrow} \cdot \mathrm{H}+\mathrm{e}_{\text {solv }}^{\ominus}+\cdot \mathrm{OH}+\mathrm{H}_{3} \mathrm{O}^{\oplus} \\
& \mathrm{CH}_{3} \mathrm{CH}_{2} \mathrm{OH} \underset{-\mathrm{H}_{2} \mathrm{O}\left(-{ }^{-} \mathrm{H}_{2}\right)}{\longrightarrow} \mathrm{CH}_{3} \dot{\mathrm{C}} \mathrm{HOH}
\end{aligned}
$$

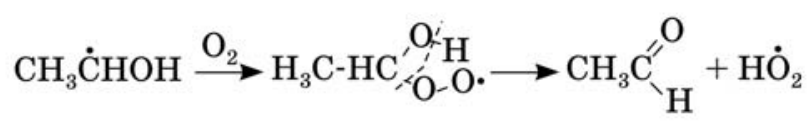

$$
\begin{aligned}
& 2 \mathrm{HO}_{2} \longrightarrow \mathrm{H}_{2} \mathrm{O}_{2}+\mathrm{O}_{2}
\end{aligned}
$$

Поскольку константы скорости взаимодействия добавок и этанола с $\cdot \mathrm{OH}$ и $\cdot Н$ являются величинами одного порядка, то при радиолизе $1 \mathrm{M}$ водного раствора этанола в присутствии 1 мМ тестируемых соединений радикальные продукты радиолиза воды будут практически полностью реагировать со спиртом с образованием $\alpha$-ГЭР. Влияние добавок на выходы молекулярных продуктов радиолиза оксигенированного $1 \mathrm{M}$ раствора этанола будет обусловлено их взаимодействием с $\alpha$-ГЭР, $\mathrm{HO}_{2}$ • и пероксильными радикалами, образующимися в реакции (10). При эквимолярном соотношении концентраций спирта и тестируемых соединений, в случае радиолиза $10^{-3} \mathrm{M}$ растворов этанола, растворенные вещества будут вступать в конкуренцию за радикальные продукты радиолиза воды. Степень подавления выходов основных молекулярных продуктов радиолиза будет определяться соотношением констант скорости реакции $\cdot \mathrm{OH}$ и $\cdot \mathrm{H}$ с тестируемыми веществами и этанолом.

АК эффективно подавляет образование основных молекулярных продуктов радиолиза деаэрированного $1 \mathrm{M}$ водного раствора этанола при $\mathrm{pH} 7$ за счет восстановления $\alpha$-ГЭР по реакции [10]:

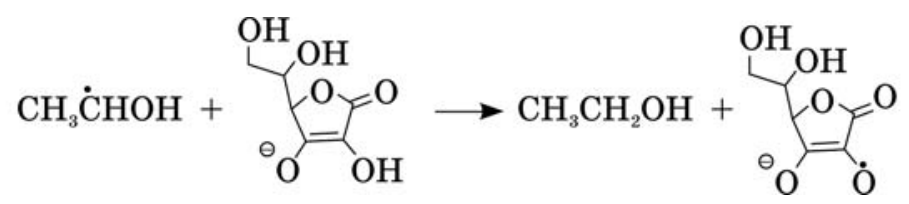


В то же время представленные в табл. 1 данные свидетельствуют о том, что при радиолизе оксигенированных растворов этанола при рН 7 АК лишь незначительно снижает радиационно-химические выходы ацетальдегида и пероксида водорода, одновременно наблюдаются высокие выходы разложения добавки, свидетельствующие об интенсивном расходовании АК в радикальных реакциях. Это указывает на то, что помимо восстановления $\alpha$-ГЭР по реакции (12), приводящей к снижению радиационно-химических выходов ацетальдегида и пероксида водорода, при радиолизе оксигенированных водных растворов этанола при $\mathrm{pH} 7 \mathrm{AK}$ может быть вовлечена в реакции, в результате которых образуются дополнительные количества радикальных частиц, например:

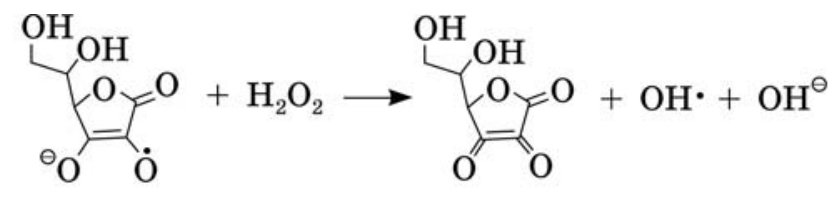<smiles>O=[O+]OC(=O)C1C(=O)OC(=O)C1C(O)O</smiles>

Низкие радиационно-химические выходы разложения ГАК и отсутствие влияния на выходы молекулярных продуктов радиолиза оксигенированных растворов этанола указывают на ее низкую реакционную способность по отношению к образующимся в данных условиях радикальным частицам. Только при радиолизе $10^{-3} \mathrm{M}$ растворов этанола за счет более высоких констант скорости взаимодействия с $\cdot \mathrm{OH}$ и $\cdot$ Н ГАК значительно снижает выход ацетальдегида. Отсутствие снижения выхода пероксида водорода в присутствии добавки может свидетельствовать о его дополнительном образовании за счет реакции типа (5).

При радиолизе оксигенированных водных растворов этанола в присутствии ИДМАК наблюдается незначительное увеличение выхода ацетальдегида и снижение выхода пероксида водорода, что указывает на способность тестируемого соединения за счет окисления $\alpha$-ГЭР по реакции (6) предотвращать окисление спиртовых радикалов по реакции (10). Наблюдаемые при радиолизе 1 мМ водного раствора этанола эффекты обусловлены акцептированием ИДМАК радикальных продуктов радиолиза воды.

\section{ВЫВОДЫ}

Представленные в работе данные свидетельствуют о том, что в эквимолярных с этанолом концентрациях аскорбиновая кислота и ее производные эффективно подавляют радиационно-индуцированные превращения этанола в оксигенированных водных растворах за счет акцептирования радикальных продуктов радиолиза воды. При увеличении концентрации этанола аскорби- 
новая кислота способна за счет восстановления, а ИДМАК - за счет окисления $\alpha$-ГЭР снижать выходы основных продуктов радиолиза оксигенированного этанола и его водных растворов при $\mathrm{pH}$ 7. Помимо способности ингибировать радиационно-индуцированные превращения оксигенированного этанола и его водных растворов при $\mathrm{pH} 7$, АК может вступать в реакции, приводящие к образованию дополнительного количества активных форм кислорода, что необходимо учитывать при рассмотрении ее роли в свободнорадикальных процессах в биосистемах.

\section{ЛИТЕРАТУРА}

1. Девис М., Остин Дж., Патридж Д. Витамин С. Химия и биохимия. М.: Мир, 1999. $176 \mathrm{c.}$

2. Halliwell B., Gutteridge J. M. C. Free radicals in biology and medicine. Oxford: University press. 1999. $936 \mathrm{c}$.

3. Violi, F., Cangemi, R., Loffredo L. Vitamin C : new research. New York: Nova Science Publishers, 2006. P. 93-119.

4. Buettner G. R., Jurkiewicz B. A. // Radiation research. 1996. Vol. 145. P. 532-541.

5. Carr A., Frei B. // FASEB Journal. 1999. Vol. 13. P. 1007-1024.

6. Olabisi A. O., Wimalasena K. // J. Org. Chem. 2004. Vol. 69, № 21. P. 7026-7032.

7. Бринкевич С. Д., Шадыро О. И. // Химия высоких энергий. 2008. Т. 42, № 4. C. $297-302$.

8. Egerton Sir A., Everett A. J., Minkoff G. J. et al. // Anal. Chem. Acta. 1965. Vol. 10. P. $422-456$.

9. Freeman G. R. Radiation chemistry of ethanol: A review of data on yields, reaction rate parameters, and spectral properties of transients. Washington: NBS. 1974. $33 \mathrm{p}$.

10. Brinkevich S. D., Shadyro O. I. // Bioorg. Med. Chem. Lett. 2008. Vol. 18. P. 6448-6450. 